\title{
Erratum
}

\section{Erratum to "Prevalence and Morphology of C-Shaped Canals: A CBCT Analysis in a Korean Population"}

\author{
Tae Yeon Lee $\mathbb{D}^{1}{ }^{1}$ Sung Eun Yang, ${ }^{2}$ and Kyung Jae $\mathrm{Kim}^{3}$ \\ ${ }^{1}$ Department of Conservative Dentistry, Yeouido St. Mary's Hospital, College of Medicine, The Catholic University of Korea, \\ Seoul, Republic of Korea \\ ${ }^{2}$ Department of Conservative Dentistry, Seoul St. Mary's Dental Hospital, College of Medicine, The Catholic University of Korea, \\ Seoul, Republic of Korea \\ ${ }^{3}$ Private Dental Clinic, Seoul, Republic of Korea \\ Correspondence should be addressed to Sung Eun Yang; dentyeun@catholic.ac.kr
}

Received 29 January 2022; Accepted 29 January 2022; Published 12 February 2022

Copyright (C) 2022 Tae Yeon Lee et al. This is an open access article distributed under the Creative Commons Attribution License, which permits unrestricted use, distribution, and reproduction in any medium, provided the original work is properly cited.

In the article titled "Prevalence and Morphology of C-Shaped Canals: A CBCT Analysis in a Korean Population" [1], the author order in the author list is stated incorrectly, and the corrected author order is shown above.

\section{References}

[1] S. E. Yang, T. Y. Lee, and K. J. Kim, "Prevalence and morphology of C-shaped canals: a CBCT analysis in a Korean population," Scanning, vol. 2021, Article ID 9152004, 8 pages, 2021. 